\title{
Pedro Azabache Bustamante: Entre el sol y la luna
}

María del Socorro MoraC de Asmat

Asociación Española de Críticos de Arte Asociación Internacional de Críticos de Arte mdelsmorac@hotmail.com

\begin{abstract}
Resumen
Pedro Azabache Bustamante (1918-2012) fue un reconocido maestro indigenista, discípulo directo del fundador del movimiento, José Sabogal (1888-1956). Este artículo es una reflexión sobre su vida y obra desde un punto de vista psicobiológico y neuroestético.
\end{abstract}

Palabras clave: Pedro Azabache, Indigenismo, Moche, maestro, personalidad, memoria, tradición, juego neuroestético

\section{Abstract}

Pedro Azabache Bustamante (1918-2012) was a renowned Indigenist Master, direct disciple of the founder of the movement, José Sabogal (1888-1956). This article is a collection of thoughts on the life and work of Pedro Azabache from a psychobiological and neurasthenic point of view.

Key words: Pedro Azabache, Indigenism, Moche, master, personality, memory, tradition, neuroaesthetics game

Realizar un ensayo sobre el maestro indigenista Pedro Azabache Bustamante ${ }^{1}$ (Moche, 1918 - Moche, 2012) debería ser una tarea sencilla por la cercanía que tuvimos con él y por las innumerables veces que conversamos a solas o con otros colegas. Pero las cosas no son tan simples, como dice Lucie-Smith: "El profundo respeto a los artistas y la tendencia a verlos como personificaciones de la consciencia nacional, debería simplificar la tarea de escribir acerca de arte latinoamericano [...] por desgracia las cosas no son tan fáciles" (Lucie-Smith, 1994:8)². De igual manera, el sentirnos inundados por la nostalgia y por la imposibilidad material de verlo en sus últimos años puede modificar nuestra plástica memoria y no ser tan objetivos con algunos hechos. Por tal motivo, sólo vamos a realizar una aproximación a los rasgos de su personalidad e incidir en lo original de su obra y su búsqueda neuroestética.

1 Nosotros vamos a referirnos a él en este artículo como siempre lo nombrábamos, con toda la admiración que nos inspiraba: Don Pedro Azabache.

2 La elipsis es nuestra. 
Recordar la semblanza de Don Pedro Azabache es viajar con la memoria hacia los caminos arcillosos y polvorientos de la campiña de Moche que conducían a su casa-taller. Su imagen amable, pero también fuerte y poderosa como el espino (fig.1) de su casa muchas veces representado en sus lienzos -que se fue inclinando con el tiempo como el maestro- se apodera de nosotros y es inevitable que nos inunden imágenes del ayer en las cuales nos vemos junto a él (fig.2), ya que su generosidad era tal que maestros y jóvenes éramos siempre bien recibidos con una sencillez que sólo tienen los grandes espíritus. Neurocientíficos como el premio Nobel Eric Kandel (1999:151-178) siguen hurgando en los misterios de nuestra memoria, pero una cosa tienen muy clara: que lo que mejor recordamos es aquello que tiene un tinte emocional (Punset, 2007) ${ }^{3}$. Kandel nos dibuja la difícil tarea que tienen por delante con una metáfora:

¿Cuál será el rumbo de la nueva ciencia de la mente en los años por venir? En lo que respecta al estudio de la memoria, nos hallamos al pie de una imponente cordillera. Comprendemos algo de los mecanismos celulares y moleculares que intervienen en su almacenamiento, pero debemos avanzar a partir de allí para entender las propiedades sistemáticas de la memoria. ¿Cuáles son los circuitos neurales importantes para los diversos tipos de memoria? ¿Cómo se representan en el cerebro las representaciones internas de un rostro, una escena, una melodía? (2007/2011:482).

Nuestros recuerdos y vivencias se quedan íntimamente ligados a nuestra motivación interna. ¿Qué movía al maestro? Evidentemente ni los títulos (tardó mucho tiempo en sacar el suyo) ni los premios de los que tuvo algunos como medallas y diplomas en distintas épocas de su trayectoria ${ }^{4}$, ni siquiera la recompensa material que a la mayoría estimula e inclusive lleva al ser

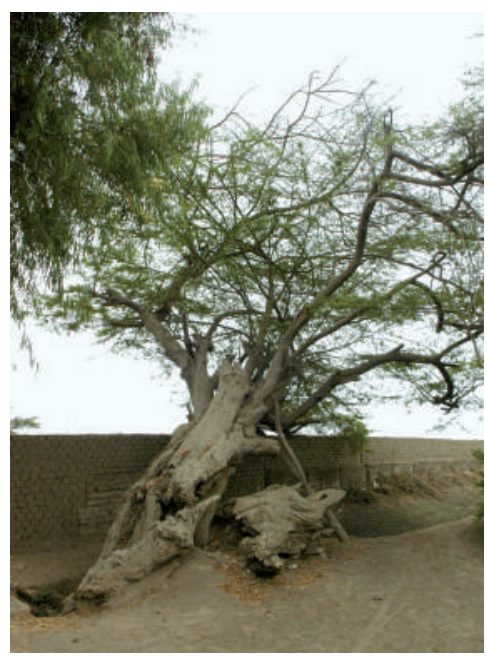

Fig.1. El viejo espino en el patio de la casa del maestro. Moche, 2005. Fotografía: Asmat Chirinos-Zavala.

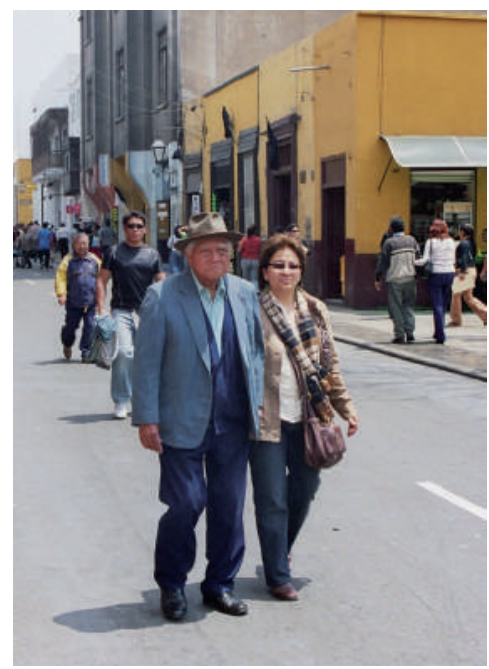

Fig.2. Pedro Azabache y $\mathrm{M}^{\mathrm{a}}$ del Socorro MoraC de Asmat, caminando en el Jirón Pizarro de Trujillo, 2007. Fotografía: Asmat Chirinos-Zavala.

3 Entrevista a Antonio Damasio.

4 Principales distinciones: 1962, Medalla de Oro y Diploma de Honor. Concejo Provincial de Trujillo / 1992 , Medalla de Oro y Diploma de Honor de la Municipalidad Provincial de Trujillo / 1996, El Gobierno Peruano le otorga el grado de "Gran Oficial"/ 1996, Declarado "Hombre del Año e Hijo Predilecto" Municipalidad de Moche / 1996, Declarado "Hijo Predilecto del Distrito de Moche y de la Provincia de Trujillo" por la Municipalidad Provincial de Trujillo / 1996, Nominado como uno de los "Líderes liberteños del siglo XX" Diario La Industria / 1996, Reconocimiento a su gran labor en el arte, Municipalidad de Puerto Malabrigo / 1996, Medalla de Oro, en Grado Simón Bolívar, Universidad Nacional de Trujillo / 2007, Declarado "Hombre del año" por la Municipalidad de Moche / 2007, "Honor al mérito" Colegio Seminario de San Carlos y San Marcelo de Trujillo / 2008, Condecorado por el Congreso de la República del Perú, con la más alta distinción y medalla de honor, en mérito a su gran labor artística / 2008, Condecorado con la "Orden Muchick" Municipalidad de Moche / 2008, Medalla de Oro y Diploma de Honor por la Municipalidad Provincial de Trujillo / 2009, Medalla de la Ciudad y Diploma de Honor. Municipalidad Provincial de Trujillo / 2011, Medalla de La Libertad concedida por el Gobierno Regional de La Libertad. 


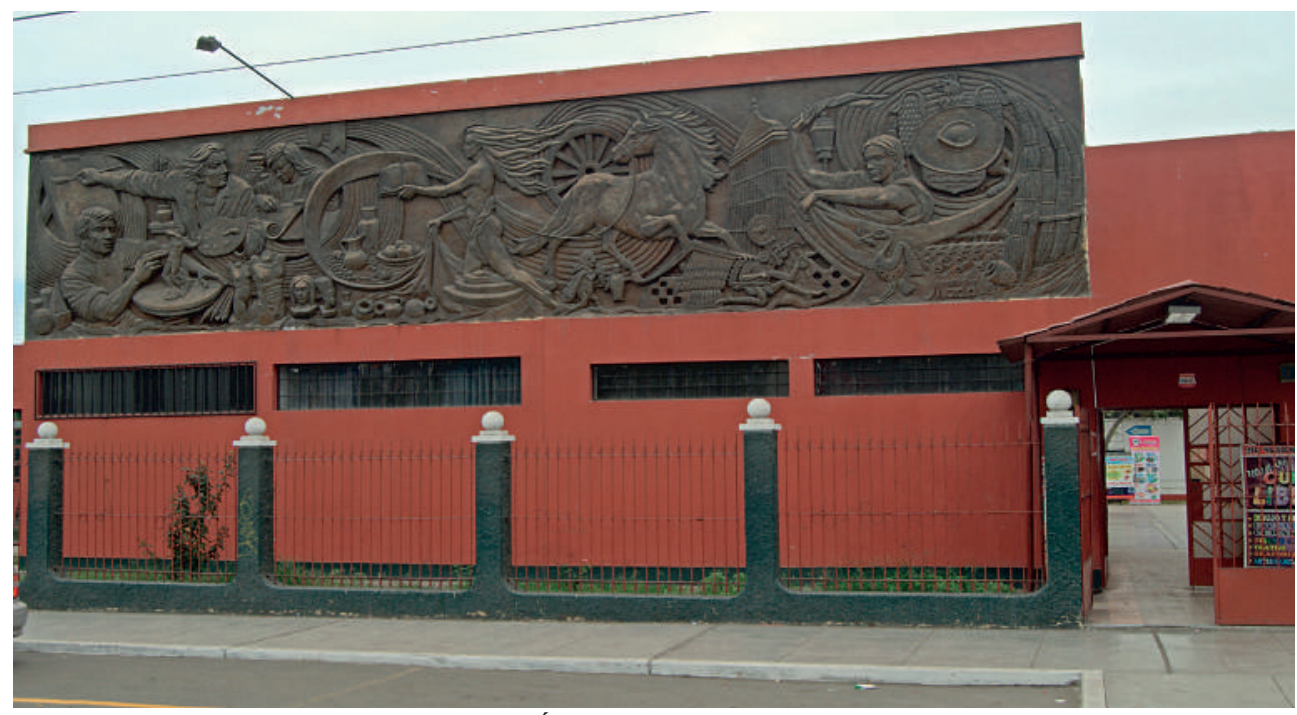

Fig.3. Mural realizado por Miguel Ángel Díaz en el frontis de la Escuela Superior de Bellas Artes "Macedonio de la Torre" de Trujillo. 1991. Fotografía: Asmat Chirinos-Zavala.

humano a desarrollar una creatividad malévola (Hao, Tang, Yang, Wang \& Runco, 2016:682). Era un ser resiliente y autotélico (Maslow, 2003:175; Seligman \& Csikszentmihalyi, 2000:514; Mc Ewen \& Gianaros 2011:431-445) movido por un sueño que sin duda le costó mucho de su tiempo y de su salud. Su motor interno era pintar y enseñar: en esa dinámica buscó el aprendizaje saliendo de su tierra para ir a la Escuela Nacional de Lima en 1937, siendo discípulo de Julia Codesido (1883-1979) y José Sabogal (1888-1956). Aunque su maestro fue conocido como dictador artístico (Lucie-Smith, 1994:76), con Don Pedro Azabache fue una feliz coincidencia de mutua admiración, y para Trujillo fue una excelente oportunidad que condujo a la construcción de un lugar en el cual se pudiesen transmitir "los memes" del arte (Dawkinks, 2002:251). Mientras muchos artistas de su generación miraban hacia el exterior (Ugarte, 1970:215-238; Traba, 2005:88-100; Lauer, 1976:44-46, Lauer, 1992:73-79), él miraba hacia adentro. Estar en el momento adecuado con las personas idóneas como Eulogio Garrido (1888-1967) quien formó un Patronato para apoyar a esta nueva institución, integrada por muchas personas de Trujillo, entre ellas: Laura Alegría, Daniela Hoyle de Roeder, Hernán Miranda Cueto, Carlos Manuel Porras, entre otros, hizo que la semilla que él guardaba en su interior, germinara. El amor a su tierra y sus costumbres fue su gran motivación. Lograr que se plasmara la idea de un centro de arte cerca de su tierra, nuestra Escuela Superior de Bellas Arte "Macedonio de la Torre" de Trujillo (1962) (fig.3), su gran herencia. Pero, en todos los entornos hay seres que no saben valorar, o simplemente son "interruptores de sueños" como los denomina Valentín Fuster (2013) y con todo tipo de estas personas, sin duda alguna, tuvo que lidiar este maestro del Indigenismo para que su profunda aspiración de que hubiese un sitio donde se cultive la sensibilidad y se enseñe arte en Trujillo, llegase a buen puerto:

Tras observarlos detenidamente durante años, he llegado a la conclusión de que estos "interruptores de sueños" se pueden clasificar en seis grandes grupos: personas con un gran complejo de inferioridad que necesitan frenar a los demás para demostrar que tienen una parcela de poder; cargos intermedios que 


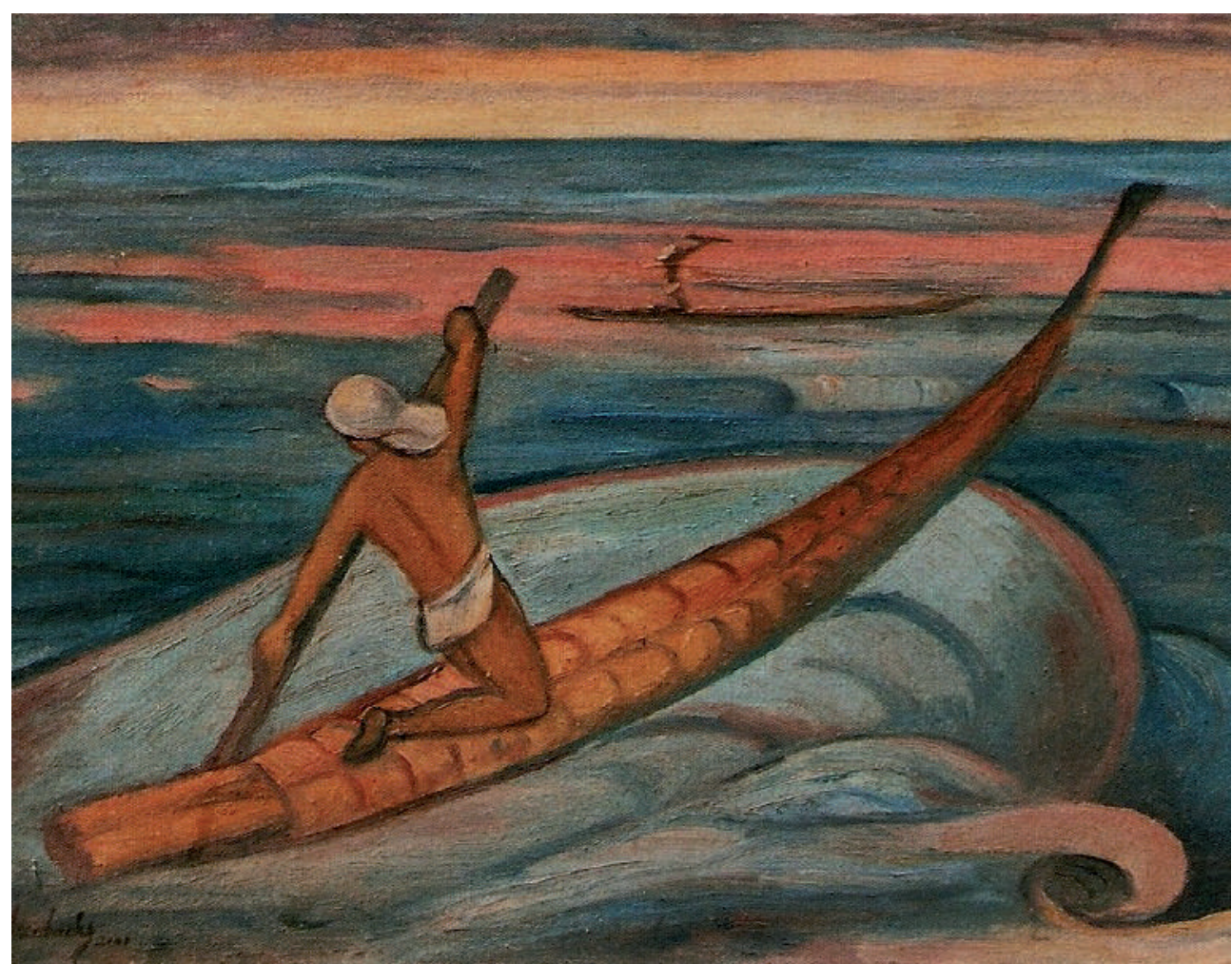

Fig.4. Huanchaquero en caballito de totora. Óleo sobre lienzo, 2005. Fotografía: Asmat Chirinos-Zavala.

intentan ascender y son prisioneros de una pulsión constante por agradar a sus superiores y trepar; individuos que no tienen maldad, pero son muy negativos y pesimistas; egomaníacos que no saben escuchar a los demás y no atienden a razones; personas con una tenebrosa confusión mental que no les permite impulsar un proyecto propio o ajeno por simple que sea; $y$, finalmente, individuos cuyo único objetivo en la vida es sobrevivir y sólo son capaces de valorar los proyectos que los mantienen a flote (Fuster, 2013:168).

Dibujar la semblanza de nuestro maestro mochero, tratando de comprender su trayectoria y su obra plástica, puede esbozarse en pocos trazos: optimista, flexible, sensible, observador, cooperativo, persistente, autosuficiente y espiritual. Muchas de estas características son mencionadas por Robert Cloninger en su Teoría Dimensional de la Personalidad en la que sugiere que para ser creativo no basta con ser organizado ya que el mundo posmoderno necesitará de seres más completos y evolucionados si queremos sobrevivir como especie (Cloninger, 2013:16-24), algo que hemos profundizado en nuestro trabajo de investigación (MoraC, 2015:143-170). Uno imagina que para lograr todo lo que hizo, Don Pedro tuvo que poseer unas conexiones neuronales que encajan en la descripción del producto de nuestra función cerebral -cuando estamos sanos- dice Alberca:

La mente es flexible, inteligente, plástica, adaptable. Lo suficiente como para aprender y acertar pese a las dificultades. Es capaz de reducir la influencia más o menos fuerte y no caer en ningún determinismo o escapar a la maldición de las circunstancias, sean cual fueren (2013:108-109). 
Un cerebro hedonista (Fox, 2012:68) es imprescindible para realizar una labor que no sólo requiere de una maestría y destreza óculo-manual, sino de pasión, persistencia, plasticidad y una exquisita capacidad para percibir y transformar su entorno en imágenes singulares (fig.4). Además, en seres como él se cumple un requisito especial: un nivel superior de consciencia; indispensable para la evolución de nuestra especie, como escribe Damasio:

Sin consciencia, es decir, sin una mente dotada de subjetividad, no tendríamos modo de conocer que existimos, y mucho menos sabríamos quiénes somos y qué pensamos. [...] Sin la subjetividad, la creatividad no habría florecido y no tendríamos canciones ni pintura ni literatura. El amor nunca sería amor, sólo sexo. La amistad habría quedado en mera conveniencia cooperativa. El dolor nunca se habría convertido en sufrimiento, no se habría considerado algo malo, sino sólo una dudosa ventaja dado que el placer tampoco se hubiera convertido en dicha o en gozo. Si la subjetividad no hubiera hecho su radical aparición, no existiría el conocimiento ni tampoco nadie que se fijara en las cosas y dejara constancia de ellas; es decir, no habría cultura ni historia de lo que las criaturas hicieron a lo largo de las épocas (Damasio, 2010:20-21) .

Y ese nivel superior de consciencia permitió que realizara una obra coherente y sincera paralela a una filosofía que intentaba reivindicar los valores tradicionales en un mundo que se iba volviendo cada vez más deshumanizado y globalizado. Tanto en el catálogo Cuatro Décadas (2003) como en el de los 50 años de la ESBAT (MoraC, 2012:5) ${ }^{6}$, mencionamos la influencia del maestro en los primeros alumnos de la escuela a los cuales les aconsejaba que: "no olviden el lugar donde nacieron y su entorno, donde hay tanta belleza para pintar y viajar por el Perú entero para dejar así un mensaje peruano” (MoraC, 2003:9). Hasta el final de sus días persistió en su labor y contribuyó con su ejemplo a que Trujillo siga siendo otro centro importante en el arte peruano (MoraC, 2007:13-16). En este mundo tan acelerado en el que no tenemos la política de cuidar a los tesoros vivos como lo hacen en otras culturas, la virtud de nuestro artista fue ser como una roca que le permitió soportar muchas injusticias. No era indiferente a lo que sucedía en el mundo del arte y al igual que Granés (2011:465) opinaba que "corrían tiempos extraños en el mundo del arte" , y no por ello dejo de interesarse en profundizar en lo que plásticamente le movía. Su admiración por la obra de Gauguin (Stuckey, Prather, 1994) denota que tenía amplitud de miras anclada en una palabra clave que es la columna vertebral de toda su obra: tradición. El juego neuroestético de sus temas emparentados con las costumbres y pasado milenario (Mujica, 2006:348) como sus marineras, caballitos de totora, paisajes de Moche, y la fiesta de San Isidro (uno de sus temas más representativos) (fig.5) se sostiene en ella; y, como bien conceptualiza Polia, tiene un trasfondo religioso y espiritual:

"Tradición" se refiere a la transmisión del patrimonio religioso de una cultura, patrimonio que abarca el conjunto de las revelaciones y mitos, el conjunto de las tradiciones religiosas, ritos, ceremonias y formas litúrgicas; las formas de transmisión iniciática; la tipología e interpretación de los símbolos; el lenguaje como vehículo de transmisión; las normas éticas y las leyes que regulan la vida social;

5 La elipsis es nuestra.

6 En este catálogo, escribíamos: "Indudablemente la respuesta inmediata que nos ahora la neurociencia y también la epigenética es que para todo aprendizaje necesita una práctica intensiva llena de pasión, energía, compromiso y un ambiente motivador con lo cual el mito del artista que nace va dejando paso a un análisis serio del entorno de aquellos que han logrado el máximo de sus capacidades. Y todos ellos tienen un común denominador: un maestro que les facilitó el aprendizaje[...] Un verdadero maestro facilita la construcción del aprendizaje, por lo tanto ahorra tiempo a la sociedad y contribuye con la eternidad ya que su conocimiento perdurará a través del tiempo y el espacio." Don Pedro Azabache Bustamante ha contribuido con la transmisión de los memes en la plástica peruana. La elipsis nuestra.

7 Azabache, Comunicación personal, 2010. 


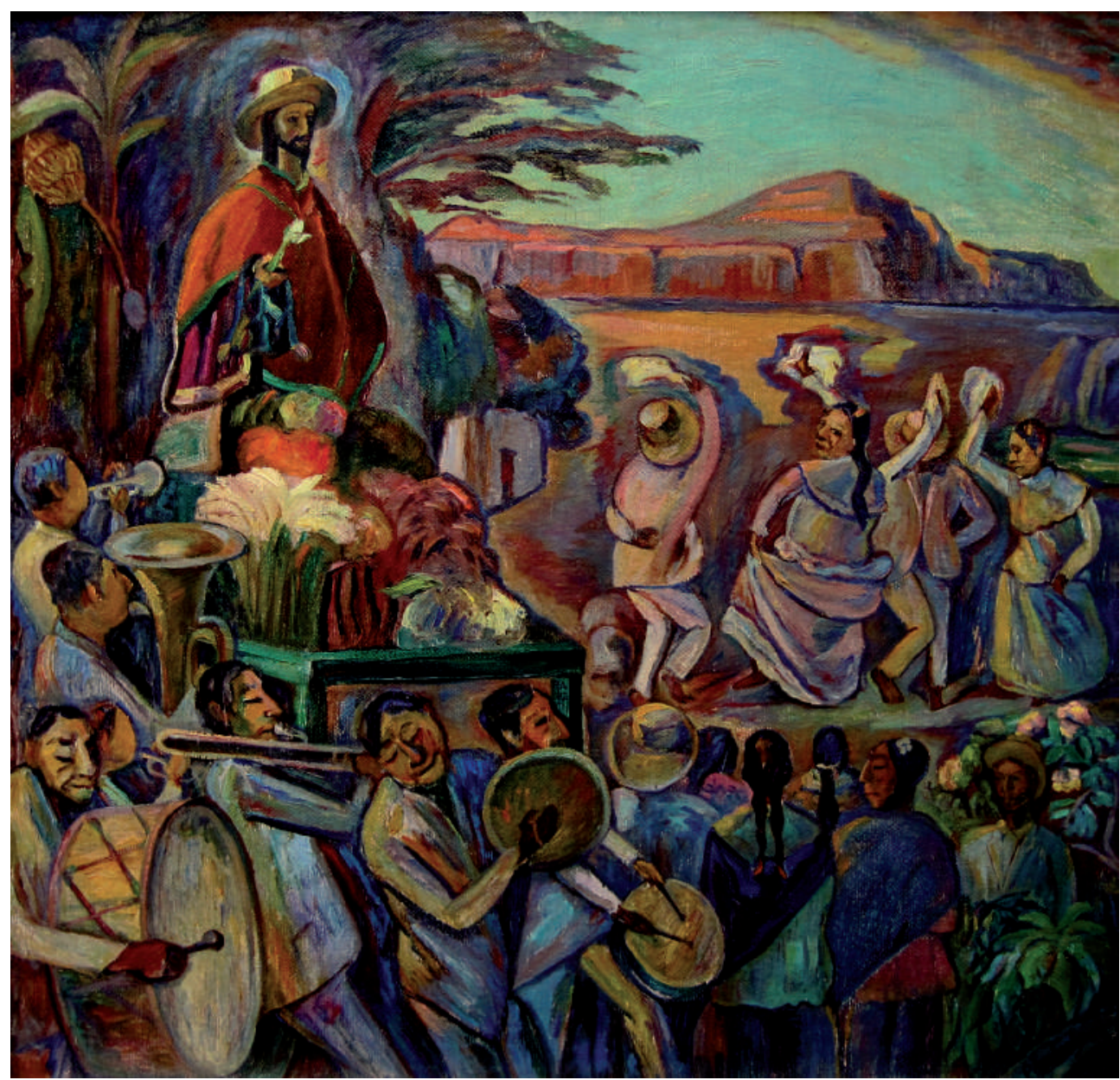

Fig.5. Homenaje a San Isidro Labrador. Óleo sobre lienzo, 1982. Fotografía: Archivo del Centro de difusión cultural Pedro Azabache.

la teoría y práctica médica; las expresiones artísticas. El concepto de "tradición” como "transmisión" del patrimonio religioso de persona a persona y de edad en edad, a su vez, presupone en todas las culturas tradicionales una primera transmisión procedente de lo divino a lo humano. En otras palabras: toda tradición presupone una revelación originaria por parte de una entidad divina, o de un "héroe cultural". "Tradicional", por lo tanto, se refiere no sólo a las formas históricas sino a la cosmovisión de aquellas culturas que no separan la dimensión del mito y la realidad cotidiana y que consideran los mitos historias sagradas y modelos ejemplares de toda actividad humana. En este sentido, el mismo concepto de cultura "tradicional" y todas las expresiones y campos de acción de la misma (entre ellas se encuentra la medicina) está profundamente vinculado con lo religioso, es decir con lo mítico y lo ritual (Polia, 2000:47-47).

Don Pedro Azabache no sólo se acercó, por medio de su obra, a las manifestaciones populares como las fiestas o las faenas de pesca o agricultura. También estaba interesado en los 


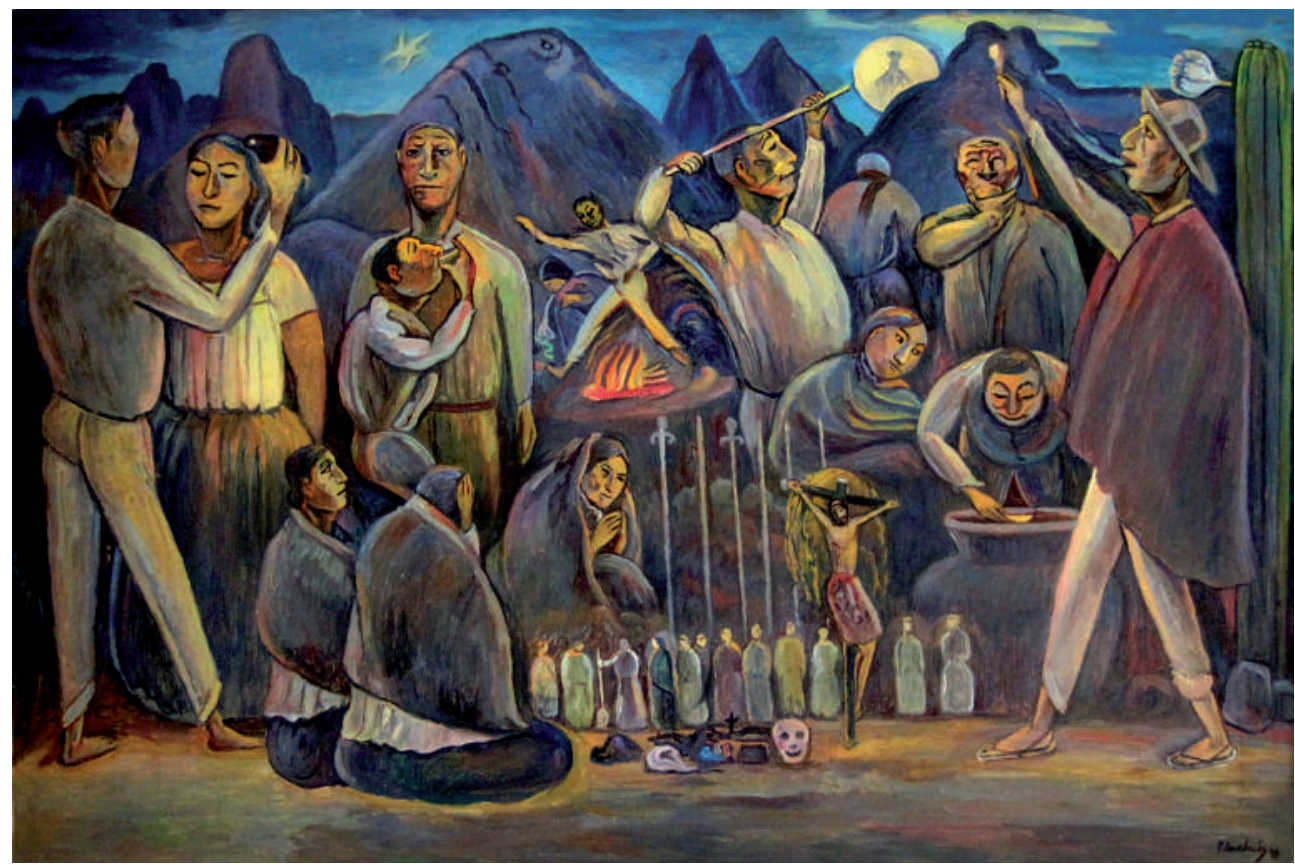

Fig.6. Curanderismo. Óleo sobre lienzo, 1996. Fotografía. Archivo del Centro de difusión cultural Pedro Azabache.

mitos, leyendas, rituales mágico religiosos transmitidos de generación en generación (fig.6). En todos ellos prima un excelente manejo del espacio y del color con una cierta tendencia simbolista a veces; mientras que en otras, por lo abigarrado de la composición, podría decirse que roza con lo naif. Sin embargo hay aspectos de su obra, menos conocidos, que merecen una profunda investigación. Vivir en un entorno lleno de mitos, entre las huacas del sol y la luna (Longhena \& Alva, 2005:136-153), entierros o en otras palabras, en una zona arqueológica, sin duda condicionó su percepción y su visión de otras dimensiones de las que pocos son conscientes. La física cuántica habla ahora de mundos paralelos, algo que nosotros no podemos controlar porque está manejados por las leyes del azar y la necesidad. Don Pedro Azabache intuía estos planos a los cuales no todos tienen acceso y estaba interesado en un tema, los gentiles, que han sido objeto de estudio, tal como los describe Polia:

Los gentiles, son los antiguos que pertenecieron a la primera época del mundo. Gigantes y longevos, dotados de sabiduría y fuerzas descomunales las emplearon para lograr el mal y la destrucción de su misma raza. Ignaros de leyes y de normas morales, vivían en la promiscuidad y en el caos hasta que Dios, cansado de ellos, los abrasó con un diluvio de fuego, o los anegó bajo las aguas abriendo los reservados del cielo. Pero no todos murieron porque, a través de sus plantas, sus brujos-videntes pudieron vislumbrar las intenciones de Dios y así precaverse y esconderse en grietas profundas y cuevas donde aún se encuentran sus restos (Polia, 2000:89).

Estos personajes, de los cuales solía hablar el maestro, tenían relación con los ancestros, y le provocaban reflexiones sobre la naturaleza humana, las luces y sombras que tiene nuestra especie como la bondad, la espiritualidad o la violencia y la codicia. Desafortunadamente, tanto las ideas sobre los gentiles o los milagros de San Isidro de los cuales alguna vez nos 


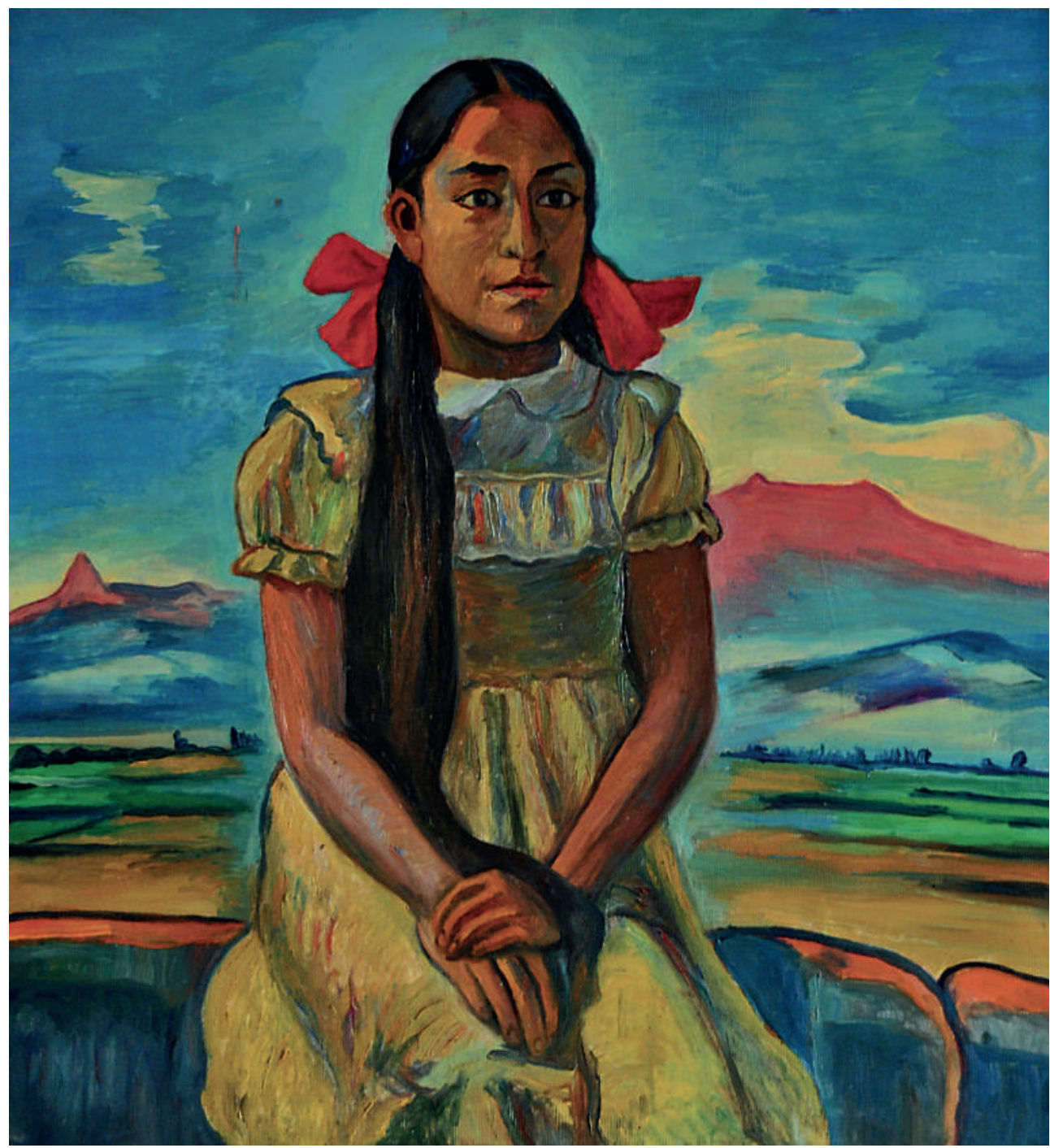

Fig.7. Flora. Óleo sobre lienzo, 1986. Fotografía: Asmat Chirinos-Zavala.

habló ${ }^{8}$, no llegaron a concretizarse. Quizá, al igual que Nieto Ulibarri ${ }^{9}$ (Zuzaga, 1989:7) le gustaba contemplar todos los aspectos de un tema antes de llevar a cabo un proyecto importante dentro de su producción neuroestética. Además, para realizar cualquier actividad, por simple que sea tenemos que estar integrados en un grupo humano que muchas veces es muy competitivo o indiferente, lo cual causa mucho estrés en vez de ser de apoyo o consuelo (Sapolsky, 2004:312), como también es preciso estar en armonía con nosotros mismos para que nuestro cuerpo responda a las exigencias físicas y mentales de nuestro

8 Azabache, Comunicación personal, 2010.

9 El pintor Enrique Nieto Ulibarri decía: “Antes de pintar un paisaje, voy a verle varias veces, para ver cómo está mejor, si con sol o nublado, por mañana o por la tarde, en invierno o en verano, etc, etc." 


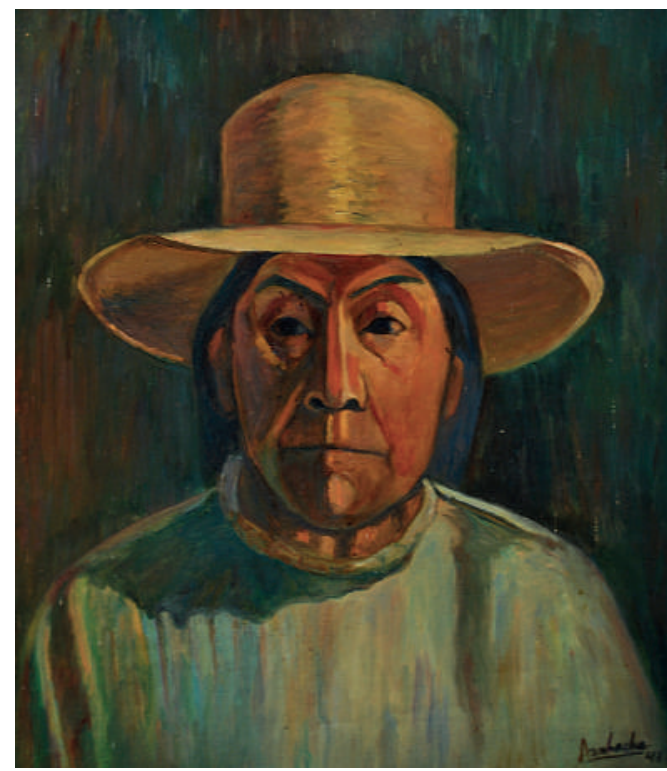

Fig.8. Retrato de mi madre. Óleo sobre lienzo, 1943. María Dolores Bustamante, madre del artista. Fotografía: Asmat Chirinos-Zavala.

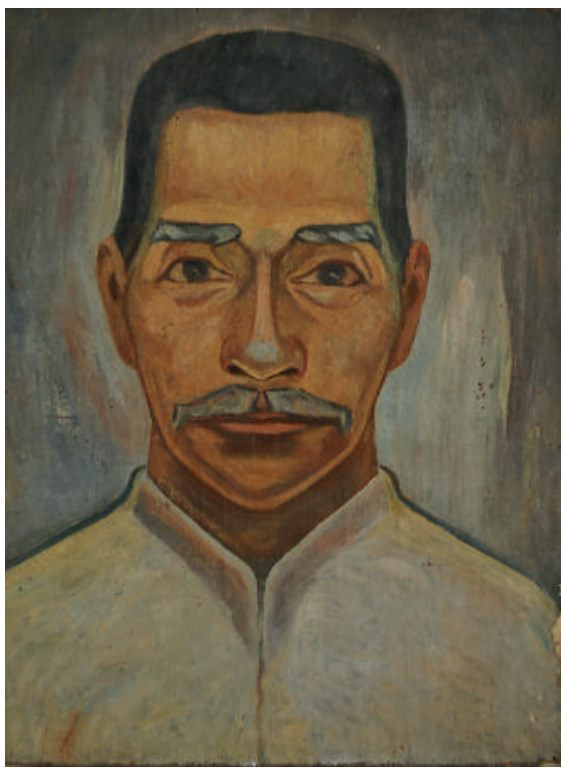

Fig.9. Retrato de mi padre. Óleo sobre lienzo, 1944. Manuel Reyes Azabache, padre del artista. Fotografía: Asmat Chirinos-Zavala.

diario vivir (O'Sullivan, 2015:194-95), algo que no todos consiguen al llegar a una edad vulnerable, como es la tercera o cuarta edad, a la cual con esos genes mochicas tan resistentes (fig.7, fig.8, fig.9), llegó nuestro maestro. Estamos seguros que si a Don Pedro le hubieran preguntado sobre la felicidad, que en el fondo es un arte (André, 2006:28) ${ }^{10}$, hubiese respondido con este poema de Li Po, porque sabía que había logrado que muchos y muchas encontraran su senda dentro del arte: “¿Me pregunta / cuál es la felicidad suprema / En este mundo? / Es oír la canción / De una niña que se aleja / Tras haberte preguntado el camino" (Ibídem:28).

\section{Referencias}

Alberca de Castro, F. (2013). Nuestra mente maravillosa. Madrid: Planeta.

André, C. (2006). El arte de la felicidad. Barcelona: Paidós.

Cloninger, R. (2013). What Makes People Healthy, Happy, and Fulfilled In The Face Of Current World Challenges? Mens Sana Monograph, 1 (11): 16-24. Recuperado de: http://www.ncbi.nlm.nih.gov/pmc/articles/ PMC3653221/ [Consulta: 21 de marzo, 2016].
Dawkins, R. (2002). El gen egoísta. Las bases biológicas de nuestra conducta. Barcelona: Salvat.

Fox, E. (2012). Una Mente Feliz. Descubre cómo funciona el Optimismo y cambia tu forma de ver la Vida. Madrid: Planeta.

Fuster, V. (2013). El círculo de la motivación. Barcelona: Editorial Planeta.

Granés, C. (2011). El Puño Invisible. Arte, Revolución y un Siglo de cambios Culturales. Madrid: Taurus.

10 El autor escribe: "los científicos, desde hace algunos años, se interesan por la felicidad de modo apasionado y atribuyen a esta emoción la denominación menos poética de 'bienestar subjetivo'. En su opinión, posee todas las virtudes: parece ser que incrementa la longevidad, mejora la salud, le hace a uno más altruista..." Podemos deducir, al contemplar su vida y obra, que nuestro artista fue un hombre feliz y autorrealizado. 
Hao, N., Tang, M., Yang, J., Wang, Q., y Runco, M. (2016). New Tool to Measure Malevolent Creativity: The Malevolent Creativity Behavior Scale. Frontiers In Psychology, 7, 682. Recuperado de: https://www.ncbi.nlm.nih.gov/pmc/articles/ PMC4870273/ [Consulta: 29 de junio 2016].

Kandel, E. (1999). Of Learning, Memory and Genetic Switches. In R. Conlan, States of Mind. New Discoveries about How Our Brains Make Us Who We Are (pp. 151-178). New York: The Dana Press.

Kandel, E. (2011 [2007]). En Busca de la Memoria. El Nacimiento de la nueva Ciencia de la Mente. Madrid: Katz.

Lauer, M. (1976). Introducción a la pintura peruana del siglo XX. Lima: Mosca Azul Editores.

Lauer, M. (1992). La pintura indigenista peruana: una visión de los años noventa. Voces de Ultramar. Arte de América Latina: 1910-1960 (pp. 73-79). Madrid: Turner Libros.

Longhena, M. y Alva, W. (2005). Perú Antiguo. Barcelona: Folio.

Lucie-Smith, E. (1994). Arte Latinoamericano del siglo XX. Barcelona: Destino.

Maslow, A. (2003). El hombre autorrealizado. Hacia una psicología del Ser (15 ed.). Barcelona: Kairós.

McEwen, B. y Gianaros, P. (2011). Stress- and Allostasis-Induced Brain Plasticity. Annual Reviews of Medicine. 62, 431-445. Recuperado de: http://www.ncbi.nlm.nih.gov/pmc/articles/ PMC4251716/ [Consulta: 24 de noviembre 2015].

MoraC, M. (2003). Tradición, vanguardia y posmodernidad en la ESBAT. Cuatro décadas: Escuela Superior de Bellas Artes "Macedonio de la Torre” (pp. 8-10). Trujillo: Gráfica Real.

MoraC, M. (2007). Trujillo arte del siglo XX: El otro centro. Trujillo arte del siglo XX: El Orden del camino (pp. 13-16). Trujillo: Arte Trujillo contemporáneo.

MoraC, M. (2012). Aprendiendo a ser artista. Arte y educación: Constructivismo, creatividad y constancia. 50 años Escuela Superior de Bellas Artes "Macedonio de la Torre" (pp. 5-6). Trujillo: ESBAT.

MoraC, M. (2015). Creatividad \& Melancolía: Un estudio psicobiológico de la dimensiones de la personalidad en el artista plástico contemporáneo (Tesis de Doctorado). Universidad Complutense de Madrid. Madrid: Asmat\&MoraC.
Mujica, M. (2006). Perú. 10.000 años de pintura. Lima: Muxica.

Polia, M. (2000). Shamanismo andino. Un perfil cultural. Shamán. La búsqueda, Alva, W., Hurtado, L., Polia, M. y Chávez, F. (ed.): 45-134. Sevilla: Scriptorium.

O' Sullivan, S. (2015). It's all in your head. Londres: Vintage.

Punset, E. (2007). Razón y diseño cerebral. Entrevista a Antonio Damasio. Recuperado de: http://bibliotecaignoria.blogspot.com/2007/03/ razn-y-diseo-cerebral-antonio-damasio.html [Consulta: 15 agosto 2016].

Sapolsky, R. (2004). Why zebras don't get ulcers. Nueva York: St. Martin's Griffin.

Seligman, M. y Csikszentmihalyi, M. (2000). Positive Psycology. An Introducction.

American Psychological Association. 1 (55), 5-14.

Recuperado de: http://www.bdp-gus.de/gus/ Positive-Psychologie-Aufruf-2000.pdf [Consulta: 15 de Agosto, 2015].

Stuckey, P. (1994). Paul Gauguin. Köln: Könemann.

Traba, M. (2005). Dos décadas vulnerables en las artes plásticas latinoamericanas, 1950-1970. Buenos Aires: Siglo XXI

Ugarte Eléspuru, J. (1970). Pintura y escultura en el Perú contemporáneo. Lima: Universitaria.

Zugaza Miranda, M. (1989). Enrique Nieto Ulibarri. 1980-1963. Bilbao: Museo de Bellas Artes de Bilbao.

Recibido el 11 de setiembre de 2016. Aceptado el 19 de octubre de 2016. 